\title{
Biomechanical effects of a novel posteriorly placed sacroiliac joint fusion device integrated with traditional lumbopelvic long-construct instrumentation
}

\author{
Bernardo de Andrada Pereira, MD, ${ }^{1}$ Jennifer N. Lehrman, MS, ${ }^{1}$ Anna G. U. Sawa, MS, ${ }^{1}$ \\ Derek P. Lindsey, MS, ${ }^{2}$ Scott A. Yerby, PhD, ${ }^{2}$ Jakub Godzik, MD, ${ }^{3}$ Alexis M. Waguespack, MD, ${ }^{4}$ \\ Juan S. Uribe, MD, ${ }^{3}$ and Brian P. Kelly, PhD'
}

\begin{abstract}
1Department of Neurosurgery, Spinal Biomechanics Laboratory, and ${ }^{3}$ Department of Neurosurgery, Barrow Neurological Institute St. Joseph's Hospital and Medical Center, Phoenix, Arizona; ${ }^{2}$ SI-BONE, Santa Clara, California; and ${ }^{4}$ SpineCare Medical Group, New Orleans, Louisiana
\end{abstract}

OBJECTIVE S2-alar-iliac (S2Al) screw fixation effectively ensures stability and enhances fusion in long-segment constructs. Nevertheless, pelvic fixation is associated with a high rate of mechanical failure. Because of the transarticular nature of the S2AI screw, adding a second point of fixation may provide additional stability and attenuate strains. The objective of the study was to evaluate changes in stability and strain with the integration of a sacroiliac (SI) joint fusion device, implanted through a novel posterior SI approach, supplemental to posterior long-segment fusion.

METHODS L1-pelvis human cadaveric specimens underwent pure moment $(7.5 \mathrm{Nm})$ and compression (400 N) tests in the following conditions: 1) intact, 2) L2-S1 pedicle screw and rod fixation with L5-S1 interbody fusion, 3) added S2AI screws, and 4) added bilateral SI joint fixation (SIJF). The range of motion (ROM), rod strain, and screw bending moments (S1 and S2Al) were analyzed.

RESULTS S2Al fixation decreased L2-S1 ROM in flexion-extension ( $p \leq 0.04)$, L5-S1 ROM in flexion-extension and compression ( $p \leq 0.004$ ), and SI joint ROM during flexion-extension and lateral bending ( $p \leq 0.03$ ) compared with S1 fixation. SI joint ROM was significantly less with SIJF in place than with the intact joint, S1, and S2AI fixation in flexionextension and lateral bending ( $p \leq 0.01$ ). The $S 1$ screw bending moment decreased following S2Al fixation by as much as $78 \%$ in extension, but with statistical significance only in right axial rotation $(p=0.03)$. Extending fixation to S2Al significantly increased the rod strain at L5-S1 during flexion, axial rotation, and compression ( $p \leq 0.048)$. SIJF was associated with a slight increase in rod strain versus S2Al fixation alone at L5-S1 during left lateral bending $(p=0.048)$. Compared with the S1 condition, fixation to S2AI increased the mean rod strain at L5-S1 during compression $(p=0.048)$. The rod strain at L5-S1 was not statistically different with SIJF compared with S2Al fixation ( $p \geq 0.12$ ).

CONCLUSIONS Constructs ending with an S2AI screw versus an S1 screw tended to be more stable, with reduced SI joint motion. S2Al fixation decreased the S1 screw bending moments compared with fixation ending at S1. These benefits were paired with increased rod strain at L5-S1. Supplementation of S2AI fixation with SIJF implants provided further reductions (approximately 30\%) in the sagittal plane and lateral bending SI joint motion compared with fixation ending at the S2AI position. This stability was not paired with significant changes in rod or screw strains.

https://thejns.org/doi/abs/10.3171/2020.11.SPINE201540

KEYWORDS iFuse; iliac fixation; rod strain; S2Al; sacropelvic fixation; SI joint; sacral

$\mathrm{S}$ ACROPELVIC fixation was introduced to adult spinal deformity (ASD) surgery to address mechanical problems associated with long fusions ending at the sacrum. ${ }^{1}$ Extending the construct down to the ilium helps to ensure a solid base of fixation that can resist substantial moments and loads present at the lumbosacral junction, serving to reduce mechanical failure and pseudarthrosis. ${ }^{2}$ Biomechanical benefits of extending the distal end of a long construct down to the ilium include protecting the S1 sacral pedicle screw from mechanical stress and providing stability similar to that of anterior column support. ${ }^{3-7}$ In the clinical scenario, the efficacy of iliac fixation was also

ABBREVIATIONS ALIF = anterior lumbar interbody fusion; $\mathrm{ASD}=$ adult spinal deformity; PSR = pedicle screw and rod; $\mathrm{ROM}=$ range of motion; $\mathrm{S} 2 \mathrm{AI}=\mathrm{S} 2$-alar-iliac; $\mathrm{SI}=$ sacroiliac; SIJF = SI joint fixation.

SUBMITTED August 18, 2020. ACCEPTED November 24, 2020.

INCLUDE WHEN CITING Published online June 18, 2021; DOI: 10.3171/2020.11.SPINE201540. 
TABLE 1. Demographic and clinical characteristics of seven human cadaveric L2-pelvis specimens

\begin{tabular}{|c|c|c|c|c|}
\hline $\begin{array}{l}\text { Specimen } \\
\text { No. }\end{array}$ & Sex & $\begin{array}{l}\text { Age } \\
\text { (yrs) }\end{array}$ & $\begin{array}{c}\text { L4 DEXA } \\
\left(B M D \mathrm{~g} / \mathrm{cm}^{2}\right)\end{array}$ & $\begin{array}{l}\text { Cause } \\
\text { of Death }\end{array}$ \\
\hline 1 & $\mathrm{~F}$ & 62 & 0.880 & End-stage renal disease \\
\hline 2 & $\mathrm{~F}$ & 49 & 0.725 & $\begin{array}{l}\text { Acute end-stage renal } \\
\text { disease }\end{array}$ \\
\hline 3 & $\mathrm{~F}$ & 66 & 0.738 & $\begin{array}{l}\text { Chronic pulmonary } \\
\text { disease }\end{array}$ \\
\hline 4 & $\mathrm{~F}$ & 56 & 0.726 & Unknown \\
\hline 5 & M & 44 & 0.811 & Cardiopulmonary arrest \\
\hline 6 & $\mathrm{~F}$ & 54 & 0.665 & Septic shock \\
\hline 7 & $\mathrm{~F}$ & 59 & 0.731 & Congestive heart failure \\
\hline $\begin{array}{l}\text { Overall, } \\
\text { mean (SD) }\end{array}$ & & $55.7(7.5)$ & $0.754(0.07)$ & \\
\hline
\end{tabular}

$\mathrm{BMD}=$ bone mineral density; $\mathrm{DEXA}=$ dual-energy $\mathrm{x}$-ray absorptiometry.

demonstrated by the reduced incidence of sacral screw breakage and pullout. ${ }^{8}$ Despite the benefits of sacropelvic fixation in ASD surgery, it is still associated with a high rate of mechanical failure. ${ }^{9}$ Different in vitro studies have also shown that the protective effect of extending fusion to the ilium on the sacral screws may come at the cost of increased strain on the rod in the lumbosacral region..$^{5,10}$

Sacropelvic fixation can be achieved in different ways, including the use of the traditional iliac screw and the S2alar-iliac (S2AI) screw technique. ${ }^{11-13}$ Besides providing stability similar to that given by a traditional iliac screw, the S2AI screw has a more medial and deeper entry point requiring less dissection and decreased skin prominence. Furthermore, the tulip head lies in line with the spinal rod, obviating the need for offset connectors. ${ }^{14,15}$ Unlike the traditional iliac screw, the S2AI screw crosses the sacroiliac (SI) joint articular cartilage, which may have unintended consequences. ${ }^{16}$

Minimally invasive stand-alone SI fixation using laterally placed triangular titanium implants with multiple points of fixation is clinically effective compared with conservative management in patients with chronic pain. Biomechanically, these implants reduce the SI joint range of motion (ROM) compared with the intact joint. ${ }^{17-25}$ In a finite element modeling study, Lindsey et al. ${ }^{26}$ reported that ROM was sequentially reduced as the number of implants placed across the SI joint increased from 1 to 3. More broadly, multiple biomechanical studies have demonstrated that a single SI joint screw results in less stability than two screws across the joint. ${ }^{27-29}$ Collectively, the above-mentioned studies corroborate the hypothesis that an increased number of fixation points increases SI joint stability.

Because of the transarticular nature of the S2AI screw, it is hypothesized that motion of the SI joint about the long axis of the screw can occur. A previous biomechanical study reported that the introduction of S2AI fixation showed minimal SI joint motion changes compared with the intact joint. ${ }^{30}$ Therefore, adding a second point of SI fixation, ideally through the same posterior approach, may provide additional stability and attenuate rod and screw strain. The objective of this study was to evaluate changes in stability and strain distribution with extension of long-segment fixation from S1 to the S2AI position and with supplemental integration of an SI joint fusion device (iFuse-3D Implant System, SI-BONE, Inc.) implanted through a novel posterior approach.

\section{Methods}

Seven fresh-frozen human cadaveric L1-pelvis specimens were selected for this study (6 female, 1 male; mean \pm SD age $55.7 \pm 7.5$ years). Medical records and plain-film radiographs were reviewed, and direct manual inspection was performed to ensure that there were no obvious pathologic conditions or SI abnormalities that might affect the results. Dual-energy x-ray absorptiometry scanning was performed on each specimen to assess bone mineral density (Table 1).

Specimens were stored at $-20^{\circ} \mathrm{C}$ until test day and then thawed in normal saline at $21^{\circ} \mathrm{C}$. Muscles and soft tissues were cleaned while keeping intact all ligaments, joint capsules, and intervertebral discs. The ischium was bilaterally reinforced with household wood screws placed in a rectangular metal mold and embedded using fast-curing resin (Smooth-Cast, Smooth-On, Inc.) to permit attachment to the base of the testing apparatus. The top vertebra (L1) was also reinforced with household screws and embedded in the same resin in a cylindrical pot (approximately 200 g) for test frame attachment and loading.

\section{Instrumentation}

All specimens were tested in the intact condition, after which polyaxial pedicle screws were inserted $(6.0 \times 45$ $\mathrm{mm}$, Stryker Corp.) from L2 to S1 with the use of fluoroscopic guidance. A wide anterior annulotomy followed by full discectomy was performed at L5-S1, and a titanium anterior lumbar interbody fusion (ALIF) implant (BASE, NuVasive, Inc.) with three $5.0 \times 25-\mathrm{mm}$ screws (one in L5 and two in S1) was placed in all specimens. Interbody spacers were sized to contact the surface of both endplates without changing the alignment. The interbody dimensions used were $6 \times 38 \times 28 \mathrm{~mm}$ with varying lordosis $\left(15^{\circ}-20^{\circ}\right)$. Two $5.5-\mathrm{mm}$-diameter titanium rods were contoured bilaterally to fit screw heads from L2 to S1 to minimize the need for reduction.

After testing the pedicle screw and rod (PSR) condition, S2AI screws $(8.5 \times 80 \mathrm{~mm}$, Stryker $)$ were bilaterally placed using fluoroscopy and connected to the rods, and each specimen was retested. For the last test condition, each specimen underwent additional SI joint fixation (SIJF) through a posterior approach. Implant sizing varied according to the anatomy of each specimen. Fluoroscopic guidance was used to ensure correct positioning. Procedures for implanting the SIJF device were performed according to the manufacturer's recommendations. Radiographs confirmed the final position of the implants. All test conditions are listed in Table 2 and illustrated radiographically in Fig. 1.

\section{Surgical Technique}

The entry point of the SIJF implant was between the 
TABLE 2. Summary of different instrumented conditions tested

\begin{tabular}{ccc}
\hline Order & Instrumentation & Anterior support \\
\hline 1 & Intact joint & No \\
\hline 2 & PSR L2-S1 & ALIF L5-S1 \\
\hline 3 & PSR L1-S2AI & ALIF L5-S1 \\
\hline 4 & PSR L1-S2AI+SIJF & ALIF L5-S1 \\
\hline
\end{tabular}

S1 and S2AI screw tulip head, at the lateral outline of the first sacral foramen. The trajectory was started with a pin and prepared using a set of probes, a drill bit, and a broach with the use of fluoroscopic guidance, and the depth was monitored using a ruler. The two main radiographic views used to guide this procedure were the "teardrop" and "inlet" views. The SIJF device crossed the SI joint and was directed above and parallel to the S2AI screw into the body of the ilium. The device was carefully advanced in the upper part of the "teardrop," whereas the S2AI screw was sited close to the inferior outline of the "teardrop" (Fig. 2). The length of the SIJF implant was chosen to be of a similar length as the S2AI screw while respecting the limits of the bone.

\section{Biomechanical Tests}

Test specimens were fixed caudally to the testing frame table to permit unconstrained relative medial-lateral translation between ilia and fixed cranially to the end effector of a 6-degrees-of-freedom robotically controlled test frame (Fig. 3). ${ }^{31}$ Specimens were subjected to dynamic nondestructive pure moment flexibility tests to $7.5 \mathrm{Nm}$ at a mean global rotation rate of $1.5^{\circ}$ per second to assess ROM stability, rod strain, and sacral screw bending moments. In each case, three cycles of a nonconstraining pure moment of flexion, extension, right and left lateral bending, and right and left axial rotation were applied, followed by three cycles of vertical gravitational compression forces to $400 \mathrm{~N}$. Data from the third cycle were analyzed for each motion.

\section{Angular Motion Tracking}

Angular ROM was obtained from a 3D motion mea-
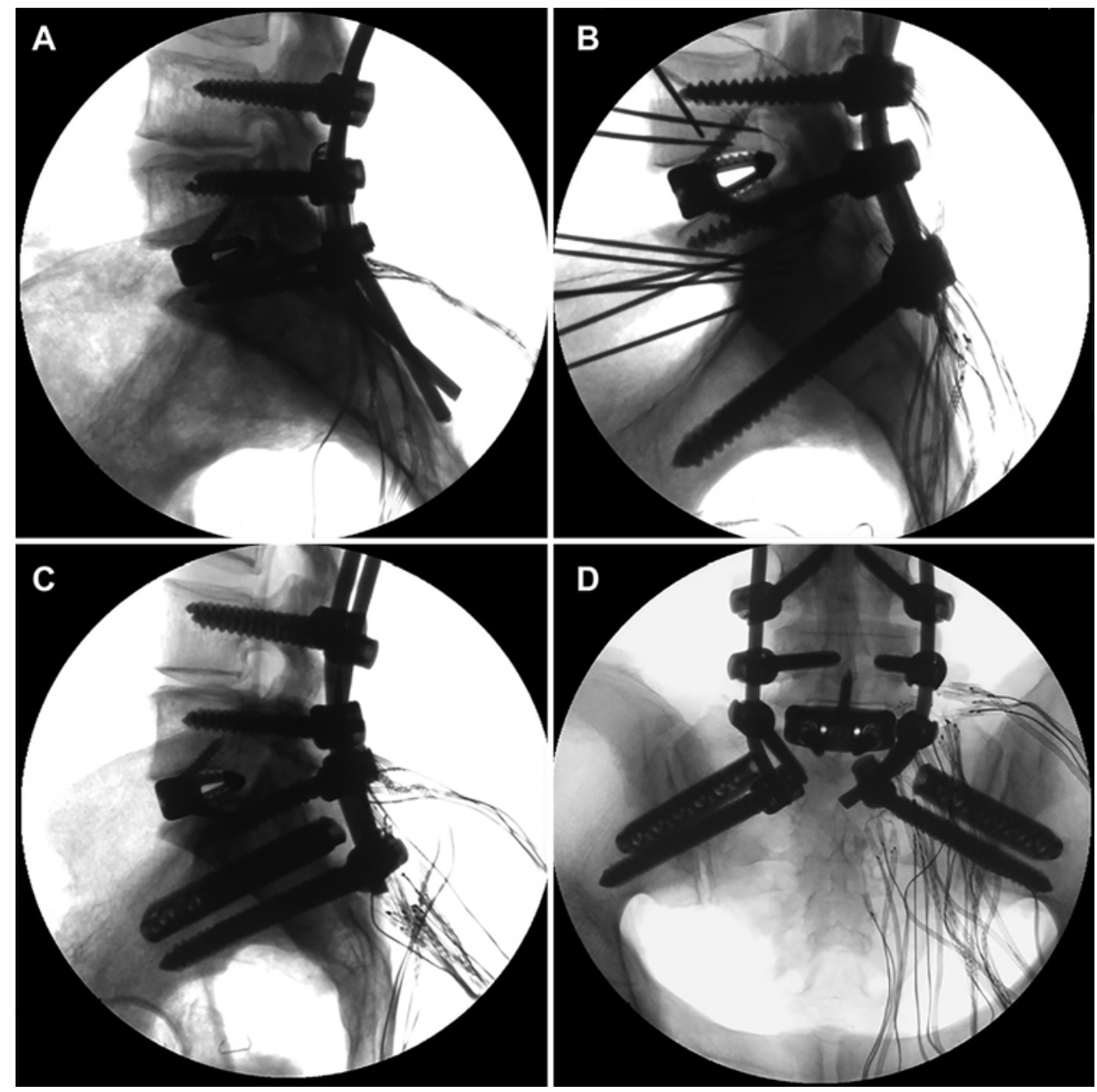

FIG. 1. Radiographic views of different instrumented spine conditions tested. Lateral views showing ALIF with S1 fixation (A), ALIF with S2Al fixation (B), and ALIF with S2AI screws and additional SIJF (C); posterior view showing ALIF with S2Al screws and additional SIJF (D). 

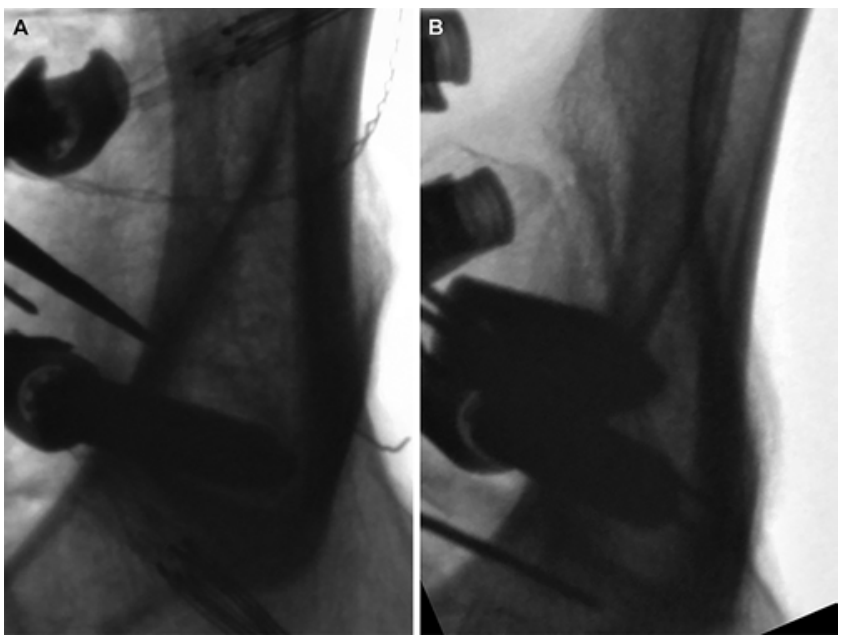

FIG. 2. A: "Teardrop" view with S2AI in place and SIJF device entry point marked by gearshift. B: "Teardrop" view with S2AI (upper) and SIJF device (lower) sharing room at the body of the ilium.

surement system with an infrared camera (Optotrak 3020, Northern Digital, Inc.). This system measured stereophotogrammetrically the $3 \mathrm{D}$ position of infrared-emitting markers attached in a noncollinear arrangement to each vertebra. Custom software was used to convert the marker coordinates to angles about each of the anatomical axes. ${ }^{32}$

\section{Screw Bending Moment and Rod Strain Monitoring}

Before insertion into the bone, each of the right-side screws intended for the L5, S1, and S2AI levels was in- strumented with four circumferentially placed uniaxial strain gauges (C2A-06-015LW-120, Micro-Measurements, Vishay Precision Group, Inc.). A loading calibration procedure was performed on each screw to establish strain versus screw bending moment relationships. ${ }^{33}$ The posterior rod intended for each specimen's right side was instrumented with stacked rosette strain gauges $(\mathrm{C} 2 \mathrm{~A}$ 06-G1350-120, Micro-Measurements) at the midlevels between L5-S1 and S1-S2AI, with the gauges facing posteriorly. The rod gauges were attached after rod contouring and were not calibrated to externally applied loads. Strain gauge placements are visible in Fig. 3. Strain monitoring was unilateral because our previous experience demonstrated no differences with respect to sides. ${ }^{34}$

\section{Statistical Analysis}

Statistical comparisons of ROM, screw bending moments, and rod strains among conditions were performed using Prism statistics version 7 (GraphPad Software Corp.), and one-way repeated-measures analysis of variance was performed followed by Holm-Sidák post hoc comparisons (as needed), assuming no sphericity and using an alpha level of $p=0.05$. A mixed model of analysis was used in cases where values were missing.

\section{Results \\ ROM}

Global (L2-S1) ROM

Compared with the intact condition, all three instrumented conditions resulted in significantly decreased L2S1 ROM in all directions of bending ( $\mathrm{p} \leq 0.004$; Table 3 ).

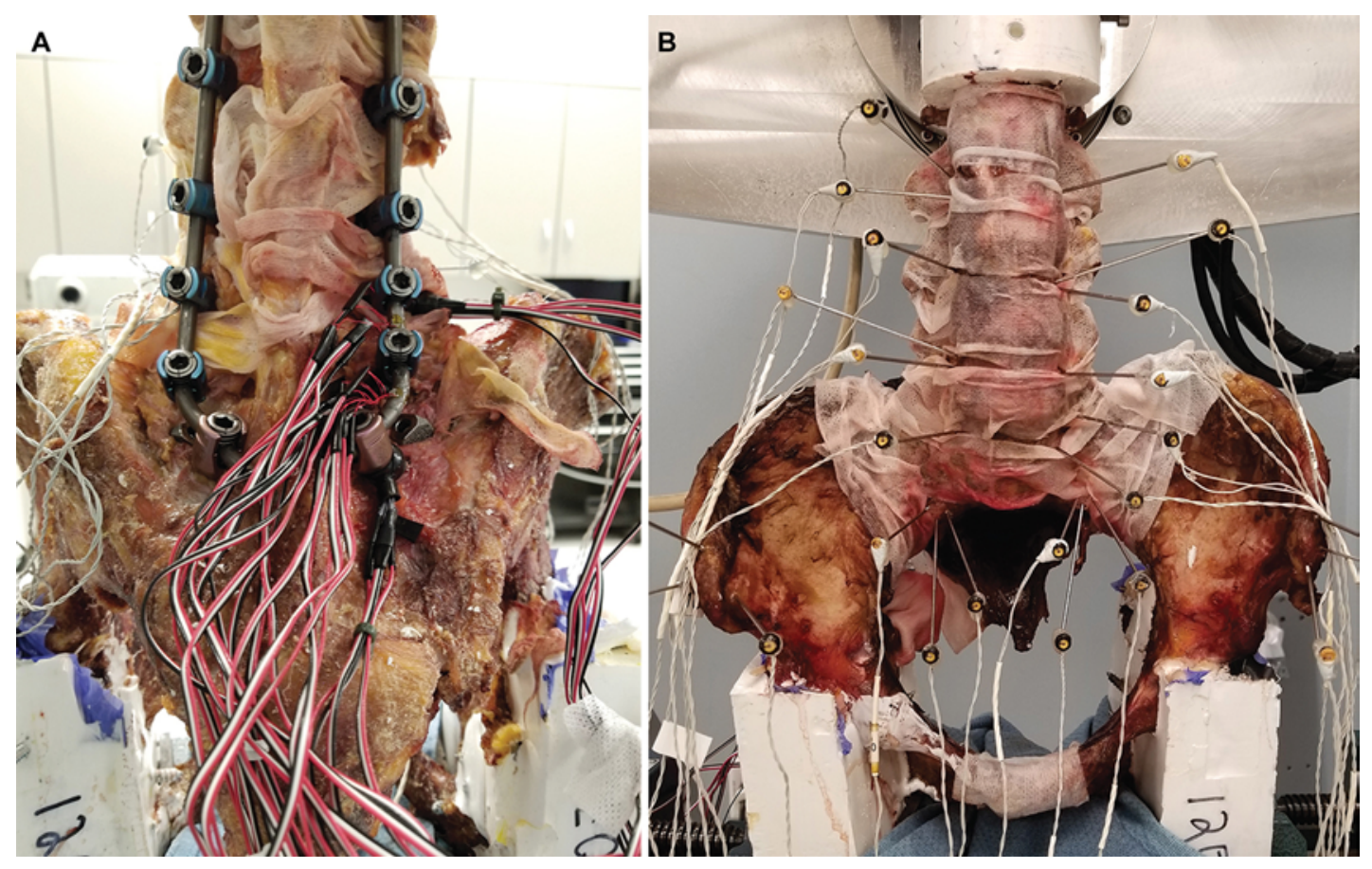

FIG. 3. Test specimen in a 6-degrees-of-freedom robotic testing frame. A: Posterior view of the specimen with rosette strain gauges visible on the right posterior rod. B: Anterior view of the specimen with optical marker arrays. Figure is available in color online only. 
TABLE 3. Mean ROM at L2-S1, L5-S1, and the SI joint

\begin{tabular}{|c|c|c|c|c|}
\hline \multirow{2}{*}{$\begin{array}{l}\text { ROM Location } \\
\text { \& Test Parameter }\end{array}$} & \multicolumn{4}{|c|}{ Mean ROM (SD), Degrees } \\
\hline & Intact & S1+ALIF & S2AI+ALIF & S2AI+ALIF+SIJF \\
\hline \multicolumn{5}{|l|}{ L2-S1 } \\
\hline Flexion & $18.35(4.38)$ & $1.13(0.24)$ & $0.92(0.21) \dagger$ & $0.98(0.26)$ \\
\hline Extension & $-14.83(3.06)$ & $-1.67(0.61)$ & $-1.10(0.36)$ & $-1.23(0.33)$ \\
\hline Lt lateral bending & $-16.42(4.64)$ & $-0.97(0.39)$ & $-1.00(0.45)$ & $-1.08(0.52)$ \\
\hline Rt lateral bending & $14.82(4.09)$ & $0.95(0.34)$ & $0.99(0.40)$ & $1.13(0.54)$ \\
\hline Lt axial rotation & $6.53(2.00)$ & $2.13(0.60)$ & $1.80(0.38)$ & $1.95(0.50)$ \\
\hline Rt axial rotation & $-6.24(1.38)$ & $-2.23(0.68)$ & $-2.12(0.61)$ & $-2.21(0.67)$ \\
\hline Compression & & $0.88(0.21)$ & $0.65(0.23)$ & $0.71(0.32)$ \\
\hline \multicolumn{5}{|l|}{ L5-S1 } \\
\hline Flexion & $4.91(1.61)$ & $0.43(0.30)$ & $0.14(0.07)$ & $0.12(0.11)$ \\
\hline Extension & $-5.55(1.39)$ & $-0.94(0.62)$ & $-0.14(0.15) \dagger$ & $-0.25(0.23)$ \\
\hline Lt lateral bending & $-3.40(1.56)$ & $-0.16(0.10)$ & $-0.10(0.04)$ & $-0.11(0.04)$ \\
\hline Rt lateral bending & $2.73(1.21)$ & $0.18(0.17)$ & $0.08(0.03)$ & $0.11(0.04)$ \\
\hline Lt axial rotation & $1.21(0.47)$ & $0.38(0.24)$ & $0.21(0.08)$ & $0.25(0.11)$ \\
\hline Rt axial rotation & $-1.27(0.41)$ & $-0.48(0.24)$ & $-0.29(0.09)$ & $-0.27(0.10)$ \\
\hline Compression & & $0.48(0.17)$ & $0.16(0.06) \dagger$ & $0.22(0.15)$ \\
\hline \multicolumn{5}{|l|}{ SI joint* } \\
\hline Flexion & $0.60(0.34)$ & $0.70(0.43)$ & $0.35(0.13)$ & $0.24(0.14) \ddagger$ \\
\hline Extension & $-0.95(0.52)$ & $-1.00(0.57)$ & $-0.35(0.17) \dagger$ & $-0.23(0.13) \dagger \ddagger$ \\
\hline Lt lateral bending & $-0.13(0.03)$ & $-0.19(0.08)$ & $-0.08(0.02) \dagger$ & $-0.06(0.03) \dagger \ddagger$ \\
\hline Rt lateral bending & $0.14(0.07)$ & $0.20(0.10)$ & $0.09(0.03) \dagger$ & $0.06(0.03) \dagger \ddagger$ \\
\hline Lt axial rotation & $0.22(0.09)$ & $0.24(0.09)$ & $0.19(0.08)$ & $0.16(0.07)$ \\
\hline Rt axial rotation & $-0.22(0.07)$ & $-0.22(0.09)$ & $-0.16(0.07)$ & $-0.17(0.07)$ \\
\hline Compression & & $0.95(0.54)$ & $0.70(0.12)$ & $0.50(0.25)$ \\
\hline
\end{tabular}

The addition of S2AI fixation significantly reduced the global ROM by $19 \%\left(0.21^{\circ}, p=0.002\right)$ in flexion and by $28 \%\left(0.78^{\circ}, \mathrm{p}=0.04\right)$ in combined flexion-extension compared with the S1 ending construct. In extension alone, the reduction was $34 \%\left(0.57^{\circ}\right)$, but this reduction was not statistically significant $(p=0.19)$. Changes in mobility following SIJF were not significant ( $\mathrm{p} \geq 0.15)$.

\section{L5-S1 ROM}

Compared with the intact condition, all three instrumented conditions resulted in significantly decreased L5$\mathrm{S} 1 \mathrm{ROM}$ in all directions of bending $(\mathrm{p} \leq 0.02)$. Compared with S1 fixation, S2AI fixation significantly reduced L5S1 ROM by $85 \%\left(0.80^{\circ}, \mathrm{p}=0.03\right), 79 \%\left(1.08^{\circ}, \mathrm{p}=0.04\right)$, and $67 \%\left(0.32^{\circ}, p=0.007\right)$ in extension, combined flexionextension, and compression, respectively. Compared with S2AI alone, L5-S1 ROM was not statistically changed with SIJF ( $p \geq 0.09$ ), except for a small but significant increase of $28 \%\left(0.05^{\circ}, \mathrm{p}=0.001\right)$ in combined lateral bending.

\section{SI Joint ROM}

Compared with the intact condition, PSR fixation ending at $\mathrm{S} 1$ did not significantly change SI joint ROM during any direction of loading $(\mathrm{p} \geq 0.07)$, except for an increase in combined lateral bending of $39 \%\left(0.11^{\circ}, p=0.03\right)$. Extending distal fixation with S2AI significantly decreased SI joint ROM by $65 \%\left(0.65^{\circ}, \mathrm{p}=0.03\right)$ in extension, by $59 \%\left(1^{\circ}, \mathrm{p}=0.02\right)$ in combined flexion-extension, by $58 \%$ $\left(0.11^{\circ}, \mathrm{p}=0.02\right)$ in left lateral bending, by $55 \%\left(0.11^{\circ}, \mathrm{p}\right.$ $=0.047)$ in right lateral bending, and by $54 \%\left(0.21^{\circ}, \mathrm{p}=\right.$ 0.01) in total lateral bending, compared with PSR ending at S1, but not during flexion, axial rotation, or compression ( $\mathrm{p} \geq 0.14)$. The SI joint mobility with added SIJF was significantly less than that for S2AI fixation in flexion, extension, combined flexion-extension, left lateral bending, right lateral bending, and total lateral bending, with the largest $\mathrm{ROM}$ reduction of $34 \%\left(0.12^{\circ}, \mathrm{p}=0.03\right)$ again in extension. No differences were noted between S2AI fixation and SIJF in axial rotation or compression $(p \geq 0.14)$.

\section{Screw Bending Moments}

\section{L5 Screw Bending Moment}

Screw bending moments at L5, S1, and S2AI are summarized in Fig. 4. Although the reduction was statistically insignificant, adding the S2AI screw reduced the mean L5 screw bending moment in extension and left and right lateral bending by $33 \%(0.07 \mathrm{Nm}), 63 \%(0.3 \mathrm{Nm})$, and $59 \%$ 

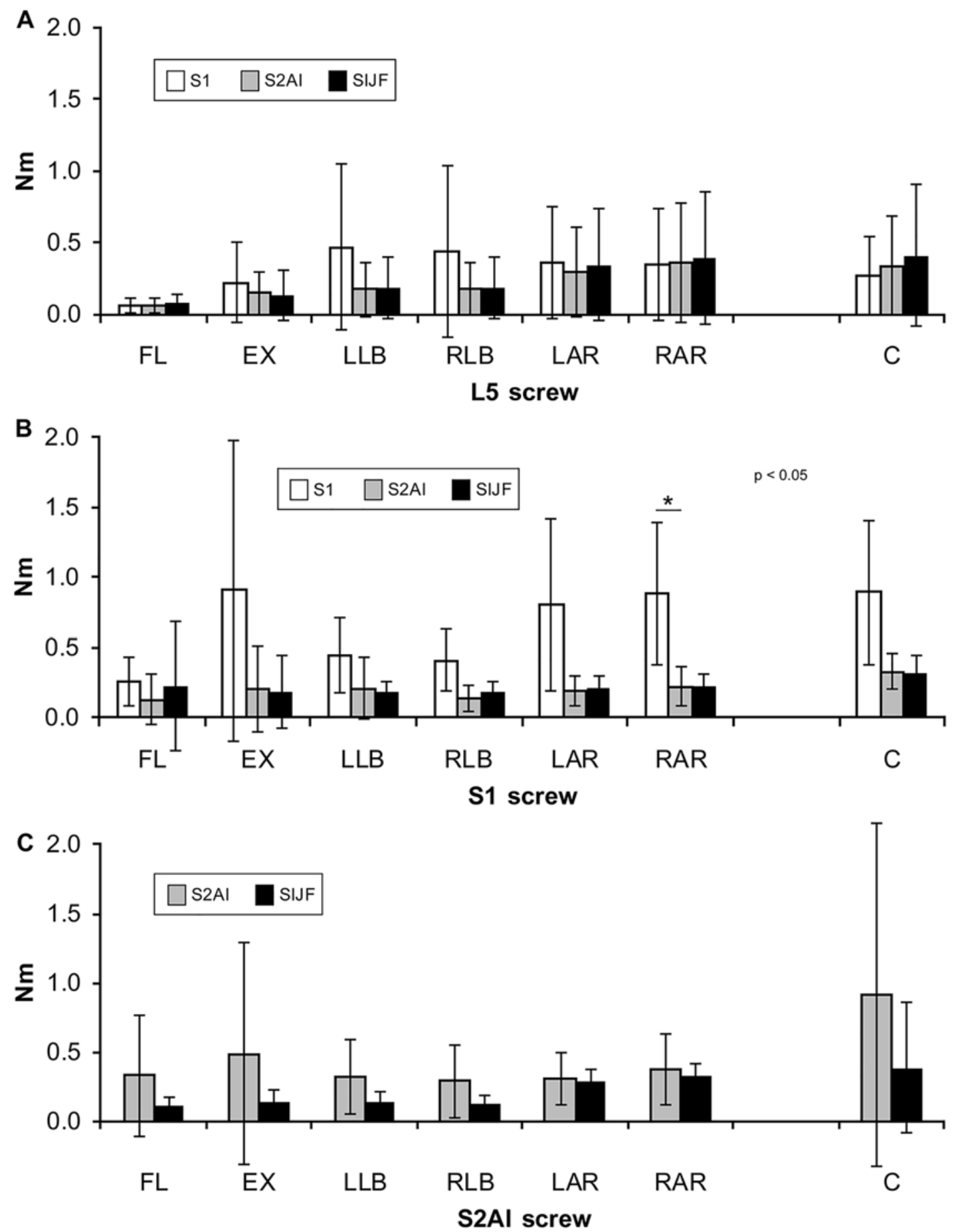

FIG. 4. L5 (A), S1 (B), and S2AI (C) mean screw bending moments during flexion (FL), extension (EX), left lateral bending (LLB), right lateral bending (RLB), left axial rotation (LAR), right axial rotation (RAR), and compression (C). Error bars show \pm 1 standard deviation. *Significantly different with respect to fixation ending at S1 (i.e., the S1 condition).

$(0.26 \mathrm{Nm})$, respectively. In all other directions of loading, the mean L5 screw bending moments were similar with the addition of S2AI screws ( $p \geq 0.25)$. Furthermore, the addition of SIJF did not substantially or significantly change L5 screw bending moments from the S2AI condition $(\mathrm{p} \geq 0.10)$.

\section{S1 Screw Bending Moment}

The addition of S2AI screws tended to reduce S1 screw bending moments during all directions of loading, with the highest magnitude of reduction of $78 \%(0.7 \mathrm{Nm})$ occurring in extension. However, the only statistically significant difference occurred in right axial rotation with a $75 \%$ 


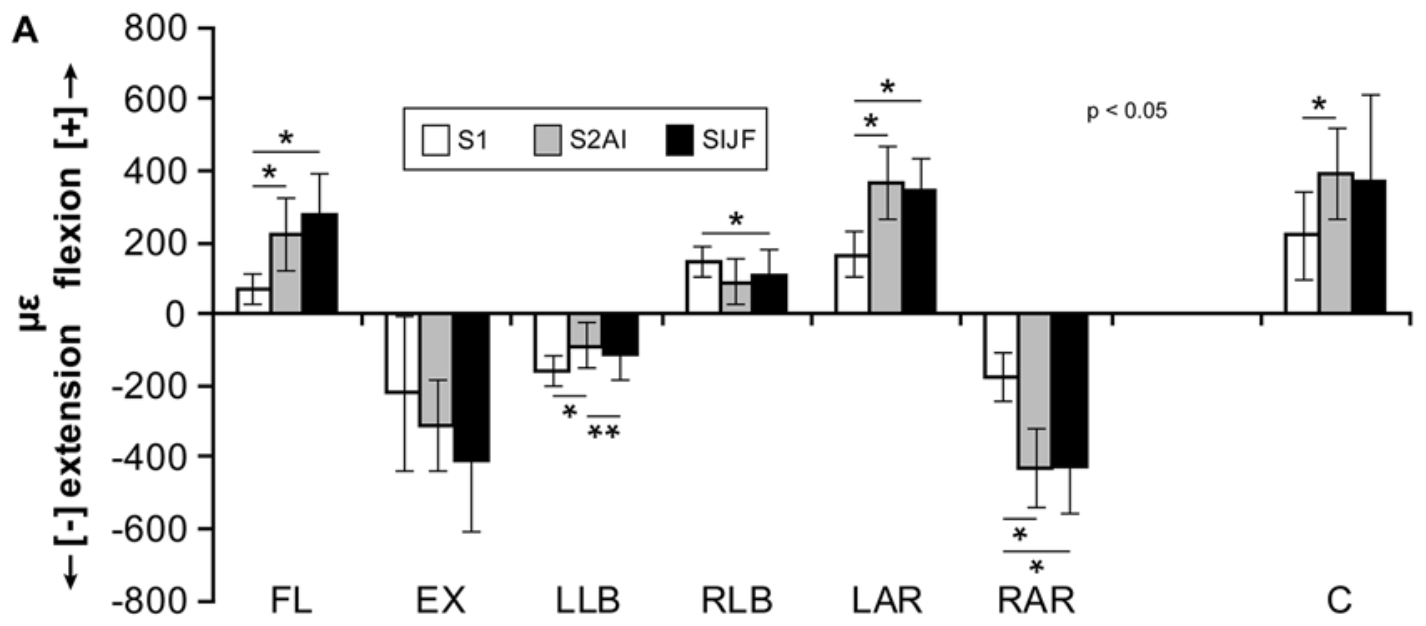

\section{L5-S1 rod primary strain}

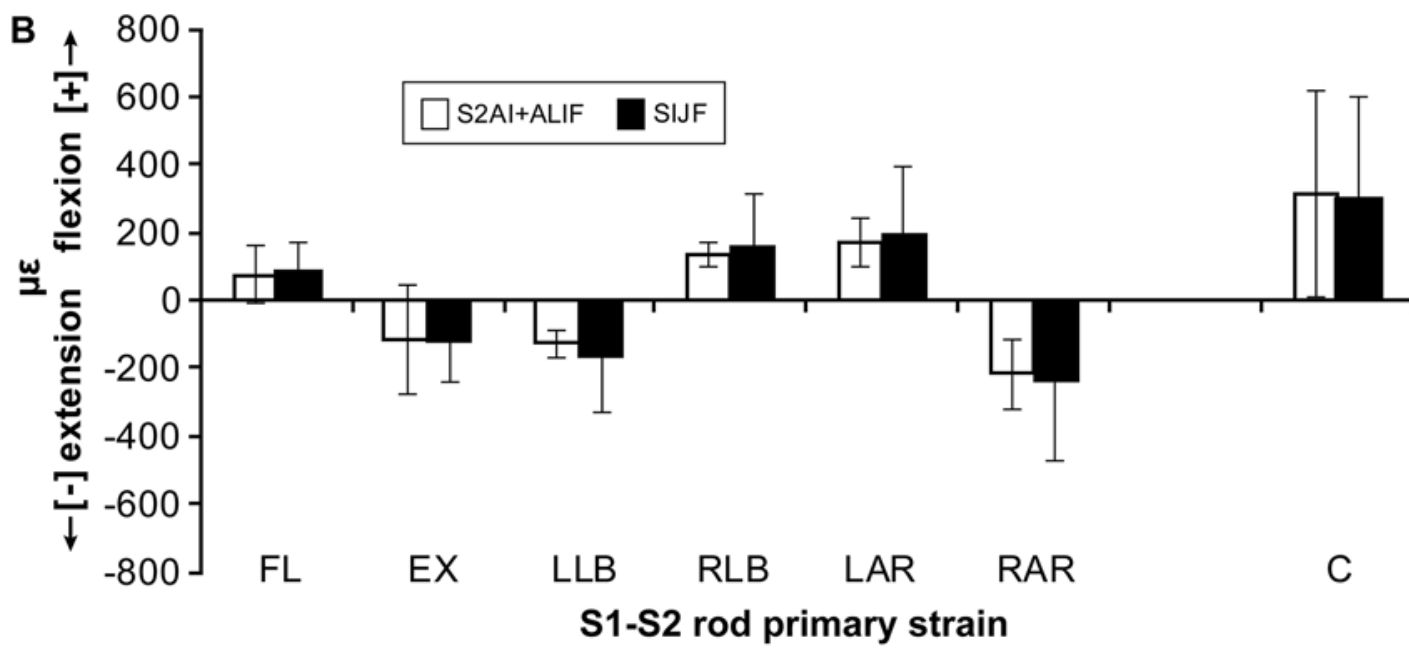

FIG. 5. Primary rod strains at L5-S1 (A) and S1-S2AI (B) during flexion (FL), extension (EX), left lateral bending (LLB), right lateral bending (RLB), left axial rotation (LAR), right axial rotation (RAR), and compression (C). Error bars show \pm 1 standard deviation. *Significantly different with respect to fixation ending at S1 (i.e., the S1 condition). ${ }^{* *}$ Significantly different with respect to fixation ending at S2Al (i.e., the S2Al condition).

reduction ( $0.89 \mathrm{Nm}$ vs $0.23 \mathrm{Nm}, \mathrm{p}=0.03)$. Furthermore, the addition of SIJF marginally changed S1 screw bending compared with S2AI fixation alone, with no significant differences between these two conditions $(p \geq 0.05)$.

\section{S2AI Screw Bending Moment}

When combined with S2AI fixation, SIJF tended to reduce mean S2AI screw bending moments in flexion, extension, and left and right lateral bending by as much as $71 \%$ $(0.35 \mathrm{Nm})$ and in compression by $58 \%(0.53 \mathrm{Nm})$. However, these reductions were without statistical significance, likely because of high variability in the data $(p \geq 0.07)$.

\section{Primary Principal Rod Strain}

\section{L5-S1 Rod Strain}

Primary rod strains at L5-S1 and S1-S2AI (derived from the respective rosette strain gauge data) are summarized in Fig. 5. With S2AI fixation, posterior L5-S1 primary rod strain increased significantly by $221 \%$ (152 $\mu \varepsilon, \mathrm{p}<0.001), 120 \%(201 \mu \varepsilon, \mathrm{p}=0.03), 141 \%(253 \mu \varepsilon, \mathrm{p}=$ $0.03)$, and $80 \%(175 \mu \varepsilon, p=0.048)$ in flexion, left axial rotation, right axial rotation, and compression, respectively, compared with fixation ending at S1. Conversely, L5-S1 rod strain was reduced in lateral bending with a significant reduction of $76 \%(69 \mu \varepsilon, p=0.048)$ in left lateral bending. Compared with the S2AI condition, the addition of SIJF slightly reduced L5-S1 strain during compression by $7 \%(27 \mu \varepsilon, p=0.63)$, negating the significant difference between S1 and S2AI fixation conditions. Compared with the S2AI condition, L5-S1 rod strain following SIJF increased significantly by $26 \%(24 \mu \varepsilon, p=0.048)$ during left lateral bending.

\section{S1-S2Al Rod Strain}

With regard to primary rod strain at S1-S2AI, the addition of SIJF to the S2AI condition had no significant effect on primary rod strain in any direction of loading $(\mathrm{p} \geq 0.12$; Fig. 5). 


\section{Discussion}

Long fusions of the lumbar spine can produce extreme cantilever moments and consequently increase motion and stress at the lumbosacral junction and SI joint ${ }^{35} \mathrm{Kim}$ et al. ${ }^{36}$ previously reported a $24 \%$ incidence of pseudarthrosis in ASD fusions terminating at S1. Pelvic fixation represents a robust foundation for long constructs ending at the sacrum with a good union rate. ${ }^{8}$ Pelvic S2AI fixation results in a single transarticular axis of fixation across the SI joint that may create an axis of rotation about which SI joint motion can still occur. With SIJF only, multiple implants have generally reduced SI joint movement. However, in the setting of an S2AI fixation, the effects of additional points of fixation across the SI joint remain unknown. The current study sought to evaluate spinal and SI joint stability, rod strain, and screw bending moments in the lumbosacral region with the extension of a long posterior rod construct to the pelvis via S2AI fixation and with an additional point of posterior SIJF that allows for long-term fusion.

Unlike the conventional lateral approach commonly used for SIJF with this device, the current study used a novel technique for placement of a single transarticular SI joint fusion device supplemental to S2AI screw fixation. The entry point of the implant was $1 \mathrm{~mm}$ lateral to the first sacral foramen, a few millimeters above the S2AI screw with a parallel trajectory, oriented approximately $20^{\circ}$ caudal in the sagittal plane and approximately $30^{\circ}$ horizontally in the coronal plane. Application of this stand-alone SIJF device, which uses the same open posterior approach as that for S2AI fixation, presents the advantages of obviating the need for additional incisions or tissue dissection and promoting fusion without the need for a direct connection with posterior rods, which may alter rod stress.

The current study demonstrated that the addition of S2AI fixation tended to create a more stable construct, as evidenced by significant reductions in global ROM, L5-S1 motion, and SI joint motion, primarily in the sagittal plane but also during lateral bending for the SI joint. In contrast with our results, Cunningham et al. ${ }^{30}$ previously reported that, although S2AI fixation decreased lumbosacral motion in several directions, the SI joint motion was not significantly reduced compared to that of the intact joint. Although their study was similar to the current in vitro study, it used an atypically high applied load limit of 12.5 $\mathrm{Nm}$, compared with the limit of $7.5 \mathrm{Nm}$ used in our study, and this discrepancy may potentially account for these differences. In the current study, the addition of SIJF had a significant stabilizing effect on the SI joint in all directions of motion except for axial rotation, compared with S2AI fixation alone.

Regarding screw bending moments, extending the construct down to the pelvis with S2AI fixation provided a small protective effect on the L5 screw bending moment in select directions (extension, left lateral bending, and right lateral bending) and a general protective effect on the S1 screw bending moment. However, a statistically significant difference was obtained only for right axial rotation. This finding was likely attributable to high variability in the data collected. Reductions in sacral screw bending moments following sacropelvic fixation have also been observed in previous biomechanical studies. ${ }^{3-5,10}$ Supple- menting S2AI fixation with SIJF did not substantially or significantly affect L5 or S1 screw bending loads. SIJF appeared to have a protective effect on the mean S2AI screw bending loads in all directions except for axial rotation, but this effect was not statistically significant, again likely because of high variability in the data.

Extending PSR fixation from S1 to S2AI significantly increased the lumbosacral posterior primary rod strain in flexion, left and right axial rotation, and compression. Lateral bending, in which rod strain decreased, was a notable exception. The maximum values of rod strain changes recorded during pure moment bending in this study occurred during extension and right axial rotation (Fig. 5). Based on the material properties of the titanium alloy (elastic modulus of 110-116 GPa), these magnitudes corresponded to less than $30 \%$ of the calculated fatigue strain of spinal rods, which had a fatigue strength of 300-389 MPa. ${ }^{37}$ However, it should be noted that strain measures in the current study were highly localized. Unknown variation in strain distribution along the rod, residual material stresses caused by rod contouring and attachment, other loading scenarios, and other factors known to increase stress, such as surface notching, may all contribute to rod fatigue and reduce the service life of the rod.

In a biomechanical study by Hlubek et al.,$^{10}$ a similar effect on rod strain was observed when PSR fixation was extended from S1 but with the use of iliac screws. However, they observed that increases were insignificant with ALIF, significant in flexion with transforaminal lumbar interbody fusion, and significant in flexion and extension with no interbody device. ${ }^{10}$ In our study, the use of anterior column support at the base of the construct aimed to simulate long-segment fusions for ASD treatment. Although ALIF demonstrated biomechanical advantages in the study by Hlubek et al., ${ }^{10}$ use of a transforaminal lumbar interbody fusion could have altered the results. Adding SIJF did not significantly increase primary posterior rod strain versus that for S2AI fixation at L5-S1, except for a small but significant increase in left lateral bending. This slight increase corresponded with the slight but significant increase in ROM at L5-S1 in combined left and right lateral bending. No substantial or significant strain changes were noted in S1-S2AI rod strain.

Overall, supplementing S2AI screw fixation with SIJF primarily improved SI joint stability in flexion-extension and lateral bending, with no appreciable influence on L5 and S1 screw strains or L5-S1 and S1-S2AI rod strains and with a tangible protective effect on S2AI screw strains. The lack of strain and screw bending moment changes in the lumbosacral region may be because the supplemental SIJF was placed independently across the SI joint and not directly linked to the PSR structure. The biomechanical effects of improved SI joint stability without adverse changes to instrumentation strain may be positively translated to the clinical setting while allowing for the longterm fusion of the SI joint. Nonetheless, increased SI joint rigidity might have other unintended or unknown adverse effects, such as mechanical stress transferred to the top of the adjacent level and the pubic symphysis or hip joints, which warrants further study. ${ }^{38}$

To our knowledge, this is the first cadaveric study to 
examine the effects of SIJF supplemental to lumbosacral long-construct fixation with S2AI fixation. Casaroli et al. ${ }^{39}$ used a finite element model to analyze the effects of sacropelvic fixation with triangular titanium devices alone, compared with iliac screws and S2AI screws as a basis of lumbopelvic fusion. The authors reported that all three forms of sacropelvic fixation reduced S1 screw (the most caudal level of fixation) stress and strain compared with PSR only; however, none were protective of L5-S1 rod strain with iliac screws increasing rod strain over PSR alone. Similarly, in the current study, S2AI fixation tended to reduce S1 screw loading. However, this was paired with significant rod strain increases at L5-S1. Although in the current study additional SI joint stabilization via added SIJF did not directly affect S1 screw strain, there was a notable protective effect at the screw in closest proximity (i.e., the S2AI screw itself). Differences in results may be attributed to differences between these two studies; for example, PSR fixation in the Casaroli model was to L4 only and without an L5-S1 interbody fusion, in contrast to the current in vitro study.

\section{Limitations}

The testing paradigm used herein evaluated immediate stability and strain distributions that can affect longer-term mechanical failure in the clinical scenario. Cyclic loading is beyond the scope of the current study and is problematic because it is not possible to truly simulate the long-term in vivo environment. That is, low-loading high-cycle paradigms with cadaver tissue tend to degrade the tissue before any instrumentation failure occurs. The absence of paraspinal and trunk muscle activity, which both play a role in stabilizing the SI joint, ${ }^{40}$ and the absence of a targeted disease mechanism that represents an indication for the surgery present further limitations. Pure moment loading is a common method for biomechanical testing but has limitations, such as the absence of other loading mechanisms, including shear. Our analysis of primary rod strain was localized and may not be reflective of overall strain distributions. The use of cross-links was deferred for experimental control. Finally, other sacropelvic fixation techniques were not tested and compared, which could have affected the results. For example, ALIF was performed in L5-S1 to simulate a long-fusion anterior basis of support and to minimize anterior column variables. However, other L5S1 interbody configurations (e.g., transforaminal lumbar interbody fusion) or no interbody fusion should be tested in future studies.

\section{Conclusions}

Long-segment constructs ending distally with S2AI screw fixation versus S1 fixation tended to create a more stable construct with significant SI joint motion reduction. S2AI fixation decreased mean S1 screw bending moments but with statistical significance only in right axial rotation when compared with fixation ending at S1. These benefits, however, were paired with increased rod strain at the lumbosacral junction. Supplementing S2AI fixation with triangular titanium implants provided further significant reductions (approximately 30\%) in the SI joint motion when compared with fixation ending at the S2AI position and provided a protective effect to the S2AI screws. This stability was not paired with notable changes in rod, or L5, or S1 screw strains.

\section{Acknowledgments}

We thank the staff of Neuroscience Publications at Barrow Neurological Institute for assistance with manuscript preparation.

\section{References}

1. Shen FH, Mason JR, Shimer AL, Arlet VM. Pelvic fixation for adult scoliosis. Eur Spine J. 2013;22(suppl 2):S265-S275.

2. Kebaish KM. Sacropelvic fixation: techniques and complications. Spine (Phila Pa 1976). 2010;35(25):2245-2251.

3. McCord DH, Cunningham BW, Shono Y, et al. Biomechanical analysis of lumbosacral fixation. Spine (Phila Pa 1976). 1992;17(8)(suppl):S235-S243.

4. Fleischer GD, Kim YJ, Ferrara LA, et al. Biomechanical analysis of sacral screw strain and range of motion in long posterior spinal fixation constructs: effects of lumbosacral fixation strategies in reducing sacral screw strains. Spine (Phila Pa 1976). 2012;37(3):E163-E169.

5. Sutterlin CE III, Field A, Ferrara LA, et al. Range of motion, sacral screw and rod strain in long posterior spinal constructs: a biomechanical comparison between S2 alar iliac screws with traditional fixation strategies. J Spine Surg. 2016; 2(4):266-276.

6. Alegre GM, Gupta MC, Bay BK, et al. S1 screw bending moment with posterior spinal instrumentation across the lumbosacral junction after unilateral iliac crest harvest. Spine (Phila Pa 1976). 2001;26(18):1950-1955.

7. Lebwohl NH, Cunningham BW, Dmitriev A, et al. Biomechanical comparison of lumbosacral fixation techniques in a calf spine model. Spine (Phila Pa 1976). 2002;27(21): 2312-2320.

8. Tsuchiya K, Bridwell KH, Kuklo TR, et al. Minimum 5-year analysis of L5-S1 fusion using sacropelvic fixation (bilateral $\mathrm{S} 1$ and iliac screws) for spinal deformity. Spine (Phila Pa 1976). 2006;31(3):303-308.

9. Guler UO, Cetin E, Yaman O, et al. Sacropelvic fixation in adult spinal deformity (ASD); a very high rate of mechanical failure. Eur Spine J. 2015;24(5):1085-1091.

10. Hlubek RJ, Godzik J, Newcomb A, et al. Iliac screws may not be necessary in long segment constructs with L5-S1 ALIF: cadaveric study of stability and instrumentation strain. Spine J. 2019;19(5):942-950.

11. Sponseller PD, Zimmerman RM, Ko PS, et al. Low profile pelvic fixation with the sacral alar iliac technique in the pediatric population improves results at two-year minimum follow-up. Spine (Phila Pa 1976). 2010;35(20):1887-1892.

12. Mattei TA, Fassett DR. Low-profile pelvic fixation with sacral alar-iliac screws. Acta Neurochir (Wien). 2013;155(2): 293-297.

13. Matteini LE, Kebaish KM, Volk WR, et al. An S-2 alar iliac pelvic fixation. Technical note. Neurosurg Focus. 2010;28(3): E13.

14. O'Brien JR, Yu W, Kaufman BE, et al. Biomechanical evaluation of S2 alar-iliac screws: effect of length and quad-cortical purchase as compared with iliac fixation. Spine (Phila Pa 1976). 2013;38(20):E1250-E1255.

15. Burns CB, Dua K, Trasolini NA, et al. Biomechanical comparison of spinopelvic fixation constructs: iliac screw versus S2-alar-iliac screw. Spine Deform. 2016;4(1):10-15.

16. O'Brien JR, Yu WD, Bhatnagar R, et al. An anatomic study of the $\mathrm{S} 2$ iliac technique for lumbopelvic screw placement. Spine (Phila Pa 1976). 2009;34(12):E439-E442.

17. Rudolf L. MIS fusion of the SI joint: Does prior lumbar spi- 
nal fusion affect patient outcomes? Open Orthop J. 2013;7: 163-168.

18. Dengler JD, Kools D, Pflugmacher R, et al. 1-year results of a randomized controlled trial of conservative management vs. minimally invasive surgical treatment for sacroiliac joint pain. Pain Physician. 2017;20(6):537-550.

19. Sachs D, Capobianco R. Minimally invasive sacroiliac joint fusion: one-year outcomes in 40 patients. Adv Orthop. 2013; 2013:536128.

20. Polly DW, Cher DJ, Wine KD, et al. Randomized controlled trial of minimally invasive sacroiliac joint fusion using triangular titanium implants vs nonsurgical management for sacroiliac joint dysfunction: 12-month outcomes. Neurosurgery. 2015;77(5):674-691.

21. Polly DW, Swofford J, Whang PG, et al. Two-year outcomes from a randomized controlled trial of minimally invasive sacroiliac joint fusion vs. non-surgical management for sacroiliac joint dysfunction. Int J Spine Surg. 2016;10:28.

22. Schroeder JE, Cunningham ME, Ross T, Boachie-Adjei O. Early results of sacro-iliac joint fixation following long fusion to the sacrum in adult spine deformity. HSS J. 2014; 10(1):30-35.

23. Soriano-Baron H, Lindsey DP, Rodriguez-Martinez N, et al. The effect of implant placement on sacroiliac joint range of motion: posterior versus transarticular. Spine (Phila Pa 1976). 2015;40(9):E525-E530.

24. Lindsey DP, Perez-Orribo L, Rodriguez-Martinez N, et al. Evaluation of a minimally invasive procedure for sacroiliac joint fusion - an in vitro biomechanical analysis of initial and cycled properties. Med Devices (Auckl). 2014;7:131-137.

25. Cross WW III, Berven SH, Slater N, et al. In vitro biomechanical evaluation of a novel, minimally invasive, sacroiliac joint fixation device. Int J Spine Surg. 2018;12(5):587-594.

26. Lindsey DP, Kiapour A, Yerby SA, Goel VK. Sacroiliac joint stability: finite element analysis of implant number, orientation, and superior implant length. World J Orthop. 2018;9(3):14-23.

27. van Zwienen CM, van den Bosch EW, Snijders CJ, et al. Biomechanical comparison of sacroiliac screw techniques for unstable pelvic ring fractures. J Orthop Trauma. 2004;18(9): 589-595.

28. Yinger K, Scalise J, Olson SA, et al. Biomechanical comparison of posterior pelvic ring fixation. J Orthop Trauma. 2003; 17(7):481-487.

29. Shih YC, Beaubien BP, Chen Q, Sembrano JN. Biomechanical evaluation of sacroiliac joint fixation with decortication. Spine J. 2018;18(7):1241-1249.

30. Cunningham BW, Sponseller PD, Murgatroyd AA, et al. A comprehensive biomechanical analysis of sacral alar iliac fixation: an in vitro human cadaveric model. J Neurosurg Spine. 2019;30(3):367-375.

31. Kelly BP, Bennett CR. Design and validation of a novel Cartesian biomechanical testing system with coordinated 6DOF real-time load control: application to the lumbar spine (L1-S, L4-L5). J Biomech . 2013;46(11):1948-1954.

32. Crawford NR, Dickman CA. Construction of local vertebral coordinate systems using a digitizing probe. Technical note. Spine (Phila Pa 1976). 1997;22(5):559-563.

33. Freeman AL, Fahim MS, Bechtold JE. Validation of an improved method to calculate the orientation and magnitude of pedicle screw bending moments. J Biomech Eng. 2012; 134(10):104502.
34. Godzik J, Hlubek RJ, Newcomb AGUS, et al. Supplemental rods are needed to maximally reduce rod strain across the lumbosacral junction with TLIF but not ALIF in long constructs. Spine J. 2019;19(6):1121-1131.

35. Ivanov AA, Kiapour A, Ebraheim NA, Goel V. Lumbar fusion leads to increases in angular motion and stress across sacroiliac joint: a finite element study. Spine (Phila Pa 1976). 2009;34(5):E162-E169.

36. Kim YJ, Bridwell KH, Lenke LG, et al. Pseudarthrosis in long adult spinal deformity instrumentation and fusion to the sacrum: prevalence and risk factor analysis of 144 cases. Spine (Phila Pa 1976). 2006;31(20):2329-2336.

37. Ohrt-Nissen S, Dahl B, Gehrchen M. Choice of rods in surgical treatment of adolescent idiopathic scoliosis: what are the clinical implications of biomechanical properties? A review of the literature. Neurospine. 2018;15(2):123-130.

38. Wood KB, Schendel MJ, Ogilvie JW, et al. Effect of sacral and iliac instrumentation on strains in the pelvis. A biomechanical study. Spine (Phila Pa 1976). 1996;21(10):1185-1191.

39. Casaroli G, Galbusera F, Chande R, et al. Evaluation of iliac screw, S2 alar-iliac screw and laterally placed triangular titanium implants for sacropelvic fixation in combination with posterior lumbar instrumentation: a finite element study. Eur Spine J. 2019;28(7):1724-1732.

40. Nagamoto Y, Iwasaki M, Sakaura H, et al. Sacroiliac joint motion in patients with degenerative lumbar spine disorders. J Neurosurg Spine. 2015;23(2):209-216.

\section{Disclosures}

D.P.L. is an employee and shareholder of SI-BONE. S.A.Y. is an employee and shareholder of SI-BONE. A.M.W. is a consultant for SI-BONE. J.S.U. is a consultant for NuVasive, SI-BONE, and Misonix.

SI-BONE provided funding and instructional support for this study. SI-BONE was not involved in the data collection or statistical analysis of the data, which was performed at an independent laboratory.

\section{Author Contributions}

Conception and design: Kelly, Lindsey, Yerby, Waguespack, Uribe. Acquisition of data: de Andrada Pereira, Lehrman. Analysis and interpretation of data: Kelly, de Andrada Pereira, Lehrman, Sawa, Lindsey, Godzik. Drafting the article: de Andrada Pereira, Godzik. Critically revising the article: Kelly, de Andrada Pereira, Lindsey, Yerby. Reviewed submitted version of manuscript: Kelly, de Andrada Pereira. Statistical analysis: Lehrman, Sawa. Administrative/technical/material support: Lehrman, Lindsey, Yerby. Study supervision: Kelly.

\section{Correspondence}

Brian P. Kelly: c/o Neuroscience Publications, Barrow Neurological Institute, St. Joseph's Hospital and Medical Center, Phoenix, AZ. neuropub@barrowneuro.org. 